\title{
Metabolism of Lignin-derived Aromatic Acids by Wood-rotting Fungi
}

\author{
By PAUL ANDER, * KARL-ERIK ERIKSSON AND HUI-SHENG YU† \\ Swedish Forest Products Research Laboratory, Box 5604, S-11486 Stockholm, Sweden
}

(Received 25 February 1983; revised 30 August 1983)

\begin{abstract}
Metabolism of ${ }^{14} \mathrm{C}$-labelled methoxyl groups in vanillic and syringic acid to ${ }^{14} \mathrm{CO}_{2}$ by various white-rot, brown-rot and soft-rot fungi was investigated in the presence of different amounts of glucose and nitrogen. In general, methoxyl metabolism in these fungi was repressed by $1 \%(w / v)$ glucose and stimulated by nitrogen. The soft-rot fungus Petriellidium boydii was the exception and metabolized the methoxyl group of vanillic acid without glucose repression. Generally, brown-rot and soft-rot fungi metabolized the methoxyl groups of syringate faster than the vanillate methoxyl group.
\end{abstract}

\section{INTRODUCTION}

Demethylation and demethoxylation are important reactions in fungal degradation of lignin as well as lignin-related phenols such as vanillic and syringic acid (Henderson, 1963; Haider \& Trojanowski, 1975, 1980; Ander \& Eriksson, 1978; Crawford, 1981; Kirk, 1981; Ander et al., 1983a). Considerable data concerning the ability of different wood-rotting fungi to demethoxylate vanillic, syringic or ferulic acids have been obtained in this laboratory in recent years (Ander et al., 1980; Gupta et al., 1981; Buswell et al., 1982a; Ander et al., 1983b; Eriksson et al., 1983). However, the metabolism of methoxyl groups required more detailed study using different media. Futhermore, apart from the studies by Henderson $(1961,1963)$ and by Haider \& Trojanowski $(1975,1980)$, very little information is available on the fungal metabolism of syringic acid. Work in this laboratory (K.-E. Eriksson, J. K. Gupta, A. Nishida \& M. Rao, unpublished results) indicated that syringate was rapidly metabolized by two soft-rot fungi and by Sporotrichum pulverulentum, but only slowly by two brown-rot fungi.

The metabolism of ${ }^{14} \mathrm{C}$-labelled methoxyl groups of vanillate and syringate to ${ }^{14} \mathrm{CO}_{2}$ have here been studied further using different glucose and nitrogen concentrations. Two common features associated with the metabolism of methoxyl groups by wood-rotting fungi seem to be repression by glucose and stimulation by nitrogen. These results have important implications for the use of wood-rotting fungi in biotechnical applications.

\section{METHODS}

Organisms. White-rot fungi: Sporotrichum pulverulentum, Nov. (ATCC 32629). This strain is the anamorph of Phanerochaete chrysosporium Burds. (S. C. Johnsrud, unpublished results). Pycnoporus cinnabarinus (Jacq. ex Fr.) Karst A-360. Pleurotus ostreatus (Jacq. ex Fr.) Kummer IPB no. 53.

Brown-rot fungi: Gleophyllum trabeum (Pers. ex Fr.) Murril A-576 (synonym Lenzites trabea). Poria placenta (Fr.) Cke. sensu J. Eriksson, synonym Poria monticola Murr.

Soft-rot fungi: Chaetomium globosum Kunze ex Fr. F 171-1 (ATCC 34152). Phialophora mutabilis (van Beyma) Schol-Schwarz 203-E-15-y-1. Petriellidium boydii (Shear) Maltoch SP 31-4.

For sources of these fungi see Buswell et al. (1982a). Poria placenta was obtained from T. Highley, FPL, Madison, Wis., U.S.A., as strain Mad. 698.

Labelled substances. Methoxyl-labelled vanillic acid $\left[{ }^{14} \mathrm{C}-\mathrm{OCH}_{3}\right.$-vanillate] $\left(1 \cdot 1 \times 10^{6} \mathrm{~d} . \mathrm{p} . \mathrm{m} . \mathrm{mg}^{-1}\right)$ and syringic acid, ${ }^{14} \mathrm{C}$-labelled in the methoxyl groups $\left(1.0 \times 10^{6}\right.$ d.p.m. $\left.\mathrm{mg}^{-1}\right)$ were gifts of Dr Konrad Haider, Institut für Pflanzenernährung und Bodenkunde, Bundesforschungsanstalt für Landwirtschaft, Braunschweig, FRG.

† Present address: Tianjin Pulp and Paper Research Institute, Tianjin, People's Republic of China. 
Cultivation. The medium used was the dimethylsuccinate (DMS) medium described by Ander et al. (1980) and Fenn \& Kirk (1979) and modified to contain $30 \mathrm{mM}$-DMS to maintain constant pH. Trace elements (Ander \& Eriksson, 1976) and $0.1 \%(w / v)$ yeast extract (Difco), probably giving 40-50 mg amino nitrogen $(1 \mathrm{medium})^{-1}$, were used in all cultivations. Glucose and nitrogen concentrations were varied as follows: $\mathrm{LH}$ medium contained $0.25 \%(\mathrm{w} / \mathrm{v})$ glucose and $20.6 \mathrm{mM}$-nitrogen as asparagine and $\mathrm{NH}_{4} \mathrm{NO}_{3}, \mathrm{HH}$ medium contained $1.0 \%$ glucose and $20.6 \mathrm{~mm}-\mathrm{N}$, while HL medium contained $1.0 \%$ glucose and $2.6 \mathrm{~mm}-\mathrm{N}$. The low nitrogen medium with $2.6 \mathrm{~mm}-\mathrm{N}$ contained $\left(1^{-1}\right) 0.10 \mathrm{~g}$ asparagine. $\mathrm{H}_{2} \mathrm{O}$ and $0.05 \mathrm{~g} \mathrm{NH}_{4} \mathrm{NO}_{3}$ while the high nitrogen medium contained eight times more of these nitrogen sources. Media were adjusted to $\mathrm{pH} 4 \cdot 2$, filter sterilized and inoculated with $1 \times 10^{6}$ spores (about $1 \mathrm{mg}$ ) of $S$. pulverulentum per $10 \mathrm{ml}$ culture medium in triplicate $125 \mathrm{ml}$ flasks. Labelled vanillic or syringic acid (about $10 \mu \mathrm{l}$ in ethanol) was added simultaneously to give about $30000 \mathrm{~d}$.p.m. per culture. Inocula of the other fungi were prepared as follows. After growth on HL medium for 7-14 d, mycelium from one or two flasks per fungus was washed with water, suspended in $50 \mathrm{ml}$ distilled water and disintegrated in a turmix. A sample $(0.5 \mathrm{ml})$ of the resulting suspension $(4-9 \mathrm{mg}$ mycelium) was then added to each culture flask. Sporotrichum pulverulentum was grown at $39^{\circ} \mathrm{C}$ and all other fungi at $28^{\circ} \mathrm{C}$. For all cultures, except Pleurotus ostreatus, the release of ${ }^{14} \mathrm{CO}_{2}$ from triplicate standing cultures was determined after absorption in $\mathrm{NaOH}$ as described by Ander et al. (1980). Pleurotus ostreatus was grown in $100 \mathrm{ml}$ flasks which were flushed with air every third day to measure ${ }^{14} \mathrm{CO}_{2}$ using the same technique adopted for measuring ligninolytic activity (Buswell et al., 1982 b). Air was used rather than oxygen for comparison of results obtained with the other fungi. If $\mathrm{NaOH}$-filled tubes were used to absorb respiratory $\mathrm{CO}_{2}$ (Ander et al., 1980), no growth was obtained with Pleurotus ostreatus.

Glucose determination. Glucose in the duplicate culture solutions was determined with GLOX, glucose oxidase reagent (Kabi Diagnostica, Stockholm, Sweden). In this method glucose is oxidized to gluconic acid with formation of $\mathrm{H}_{2} \mathrm{O}_{2}$, which reacts together with peroxidase and an aromatic amine to give a coloured product. After $60 \mathrm{~min}$, absorbance was read at $450 \mathrm{~nm}$ (Kjellman \& Rådeström, 1981) and glucose concentrations were read off against a standard curve prepared with reagent grade $\mathrm{D}$-glucose.

\section{RESULTS}

\section{Metabolism of methoxyl-labelled vanillic and syringic acids}

Different wood-rotting fungi were used to study the influence of varying glucose and nitrogen concentrations on the metabolism of ${ }^{14} \mathrm{C}$-methoxyl-labelled vanillic and syringic acids to ${ }^{14} \mathrm{CO}_{2}$. The results are shown in Figs 1-3.

The general pattern for all the fungi tested was that $\mathrm{LH}$ medium containing $0 \cdot 25 \%$ glucose and $20.6 \mathrm{~mm}$-nitrogen (as asparagine and $\mathrm{NH}_{4} \mathrm{NO}_{3}$ ) was best suited for rapid ${ }^{14} \mathrm{CO}_{2}$ evolution from the methoxyl groups of both vanillate and syringate. For two of the fungi, namely $S$. pulverulentum and Pleurotus ostreatus, HH or HL media in the later stages of the experiments gave higher yields of ${ }^{14} \mathrm{CO}_{2}$ from syringate.

The amounts of ${ }^{14} \mathrm{CO}_{2}$ liberated by the different fungi in these media varied widely. Sporotrichum pulverulentum released as much as $70 \%{ }^{14} \mathrm{CO}_{2}$ in $14 \mathrm{~d}$ from vanillate and $46 \%$ ${ }^{14} \mathrm{CO}_{2}$ from syringate in the $\mathrm{HH}$ medium. In the case of Pleurotus ostreatus, if ${ }^{14} \mathrm{CO}_{2}(+$ respiratory $\mathrm{CO}_{2}$ ) was absorbed in $\mathrm{NaOH}$-filled tubes according to Ander et al. (1980), very little fungal growth was obtained. However, flushing with air every third day (see Methods) gave good growth, and under these conditions $26 \%{ }^{14} \mathrm{CO}_{2}$ was released from vanillate in the $\mathrm{LH}$ medium after $14 \mathrm{~d}$ (Fig. 1).

Results for brown-rot and soft-rot fungi (Figs 2 and 3) show that syringate methoxyl groups are metabolized faster than vanillate methoxyl groups. For example, Chaetomium globosum released $35 \cdot 6 \%{ }^{14} \mathrm{CO}_{2}$ from syringate and only $3 \cdot 4 \%{ }^{14} \mathrm{CO}_{2}$ from vanillate in the $\mathrm{LH}$ medium.

\section{Metabolism of vanillate and syringate in relation to glucose concentration and mycelial weights}

Glucose concentrations and mycelial dry weights of the various fungi after 3,6 and $9 \mathrm{~d}$ are also shown in Figs 1-3. In the LH medium, little or no glucose was left after $3 \mathrm{~d}$ and a decrease in mycelial weight was observed for many of the fungi after $9 \mathrm{~d}$. If this low amount of mycelium is taken into consideration, the suitability of the $\mathrm{LH}$ medium for rapid ${ }^{14} \mathrm{CO}_{2}$ evolution is still more apparent.

The direct influence of glucose on ${ }^{14} \mathrm{CO}_{2}$ evolution from the methoxyl groups of vanillate and syringate is obvious for all fungi, although they differed in this respect. Sporotrichum pulverulentum, the two brown-rot fungi and the two soft-rot fungi C. globosum and Phialophora mutabilis started to evolve ${ }^{14} \mathrm{CO}_{2}$ at a rather low glucose concentration of about $0 \cdot 1 \%$ or lower. 


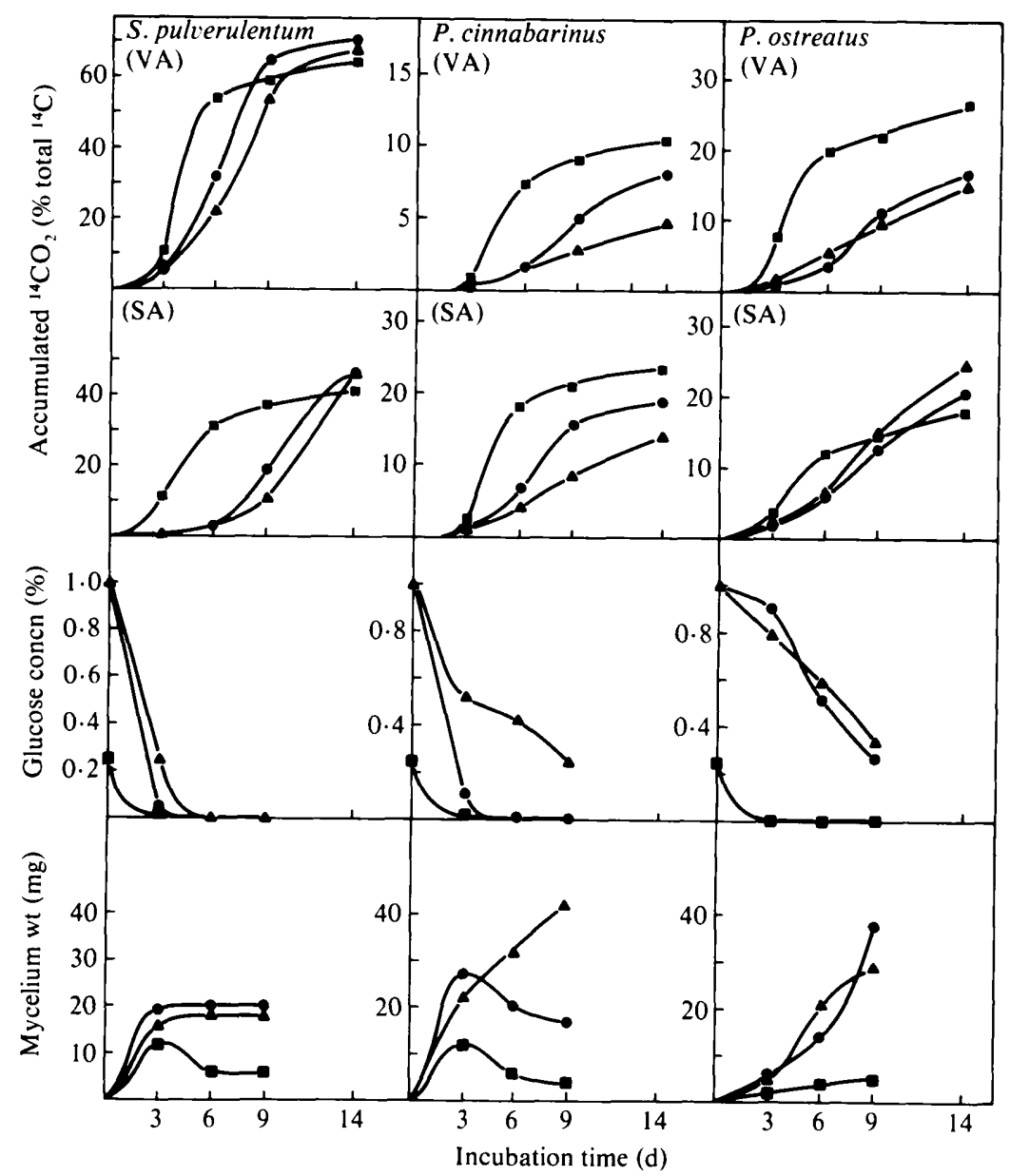

Fig. 1. Accumulated ${ }^{14} \mathrm{CO}_{2}$ evolution from $\left[{ }^{1+} \mathrm{C}-\mathrm{OCH}_{3}\right]$ vanillate (VA) and $\left[{ }^{14} \mathrm{C}-\mathrm{OCH}_{3}\right]$ syringate (SA), by the white-rot fungi $S$. pulterulentum, Pycnoporus cinnabarinus and Pleurotus ostreatus on LH ( $($ ) $(0 \cdot 25 \%, w / v$, glucose and $20.6 \mathrm{~mm}$-nitrogen $)$, HL (A) $(1 \%$ glucose and $2.6 \mathrm{~mm}-\mathrm{N})$, or $\mathrm{HH}(\mathbf{O})(1 \%$ glucose and $20.6 \mathrm{~mm}-\mathrm{N})$ media after $14 \mathrm{~d}$. Glucose concentrations in these media are shown after 3,6 and $9 \mathrm{~d}$ cultivation. ${ }^{14} \mathrm{CO}_{2}$ data are mean values from three replicate cultures. Glucose values are from duplicate cultures. Final standard deviation $\left(\delta_{n-1}\right)$ for the ${ }^{14} \mathrm{CO}_{2}$ values:
S. pulverulentum
on VA: LH, $4.2 \%$; HL, $1.2 \%$ : HH, $5.5 \%$ on SA: LH, $11.6 \%$; HL, $6.6 \%$; HH, $5.9 \%$
Pycnoporus cinnabarinus on VA: LH, $0.1 \%$; HL, $0.83 \%$; HH, $1.0 \%$ on SA: LH, $0.6 \%$; HL, $2.6 \%$; HH, $2.2 \%$
Pleurotus ostreatus on VA: LH, $10.4 \%$; HL, $5.8 \%$; HH, $3.5 \%$ on $\mathrm{SA}: \mathrm{LH}, \quad 7.4 \% ; \mathrm{HL}, 4.9 \% ; \mathrm{HH}, 2.6 \%$

Pycnoporus cinnabarinus and Pleurotus ostreatus were not so sensitive to glucose and began to evolve ${ }^{14} \mathrm{CO}_{2}$ at $0.4-0.6 \%$ glucose. Petriellidium boydii was unusual in that the rate of ${ }^{14} \mathrm{CO}_{2}$ evolution from vanillate was highest during the first $3 \mathrm{~d}$ in all three media. After $3 \mathrm{~d}$, about $13 \%$ ${ }^{14} \mathrm{CO}_{2}$ had accumulated using both $\mathrm{LH}$ and $\mathrm{HH}$ media, and glucose repression of vanillic acid methoxyl group metabolism was not apparent in this fungus. However, the metabolism of the syringate methoxyl groups was clearly repressed by glucose.

Chaetomium globosum was the best growing fungus and more than $50 \mathrm{mg}$ mycelium was obtained on $\mathrm{HH}$ and $\mathrm{HL}$ media after $6 \mathrm{~d}$. This, however, made ${ }^{14} \mathrm{CO}_{2}$ release per mg mycelium smaller as compared with, for example, $S$. pulverulentum which yielded a maximum of $20 \mathrm{mg}$ mycelium. 


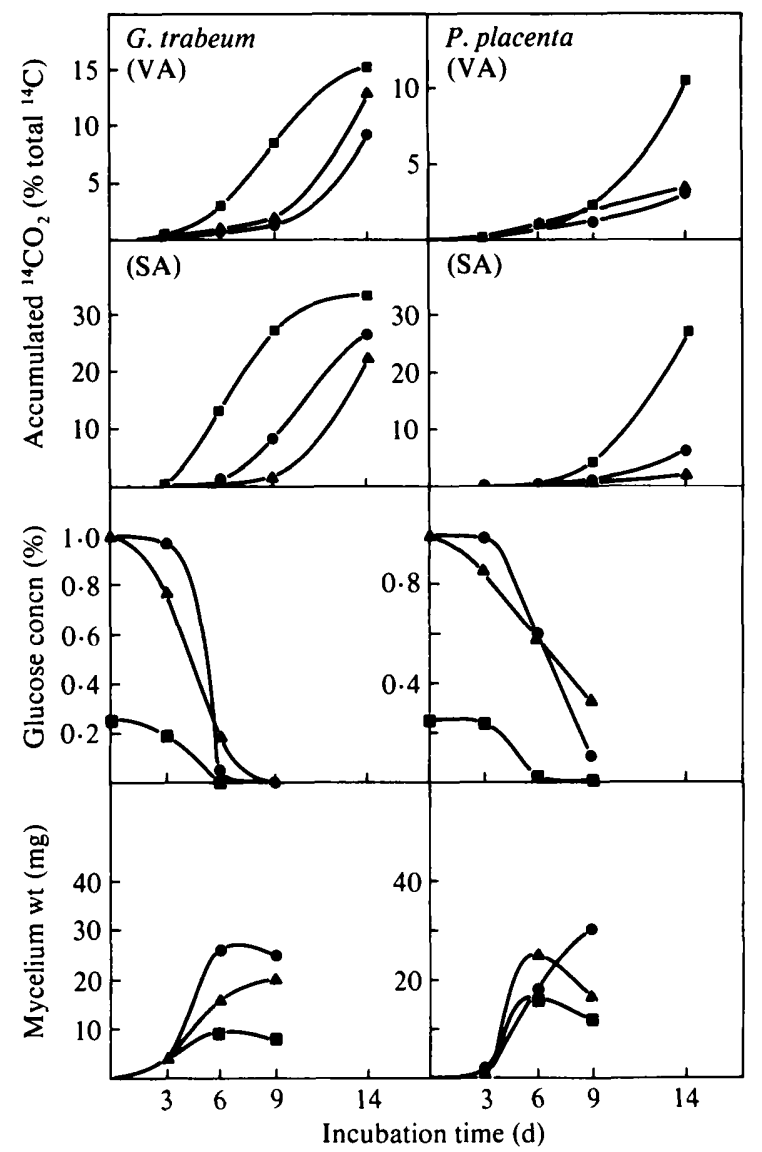

Fig. 2. Accumulated ${ }^{14} \mathrm{CO}_{2}$ evolution from methoxyl-labelled vanillate (VA) and syringate (SA) by the brown-rot fungi $G$. trabeum and Poria placenta on LH ( $\square)$, HL (A) and HH (O) media. Other conditions are as in Fig. 1. Final standard deviations $\left(\delta_{n-1}\right)$ for the ${ }^{14} \mathrm{CO}_{2}$ values:

$$
\begin{array}{llll}
\text { G. } \text { trabeum } & \text { on VA: LH, } 3.4 \% ; & \text { HL, } 2.0 \% ; & \text { HH, } 0.86 \% \\
\text { Poria placenta } & \text { on SA: LH, } 7.5 \% ; & \text { HL, } 15.4 \% ; & \text { HH, } 7.2 \% \\
& \text { on VA: LH, } 0.35 \% ; & \text { HL, } 0.15 \% ; & \text { HH, } 1.0 \% \\
& \text { on SA: LH, } 2.7 \% ; & \text { HL, } 0.15 \% ; & \text { HH, } 4.1 \%
\end{array}
$$

\section{DISCUSSION}

The data presented here indicate that for many wood-rotting fungi, the systems involved in the metabolism of lignin degradation products, such as vanillic and syringic acid, are repressed by glucose and stimulated by nitrogen. Similar results were reported earlier by Haider \& Trojanowski (1980) using Gleophyllum trabeum (Lenzites trabea) and several methoxyl-labelled phenols, among them vanillic and ferulic acids. These authors proposed that the further oxidation of the $\mathrm{C}_{1}$-compound obtained from the methoxyl group was retarded by glucose. Recent results in our laboratory (Ander et al., 1983b) support this suggestion and, in the case of Sporotrichum pulverulentum, the $\mathrm{C}_{1}$-compound has been identified as methanol.

In their studies of vanillic acid metabolism by different wood-rotting fungi, Buswell $e t$ al. (1982a) obtained $50 \%$ and $38 \%{ }^{14} \mathrm{CO}_{2}$ in $14 \mathrm{~d}$ from the methoxyl group of vanillate by Pycnoporus cinnabarinus and Chaetomium globosum, respectively. In this investigation, only $10 \%$ and $3.4 \%{ }^{14} \mathrm{CO}_{2}$ was obtained from ${ }^{14} \mathrm{OCH}_{3}$-vanillate over the same period. Further, Buswell et al. (1982a) reported less than $1 \%{ }^{14} \mathrm{CO}_{2}$ evolution from the vanillate methoxyl groups in cultures of Gleophyllum trabeum after $10 \mathrm{~d}$, whereas here $15 \% \mathrm{CO}_{2}$ was obtained in $14 \mathrm{~d}$. These 


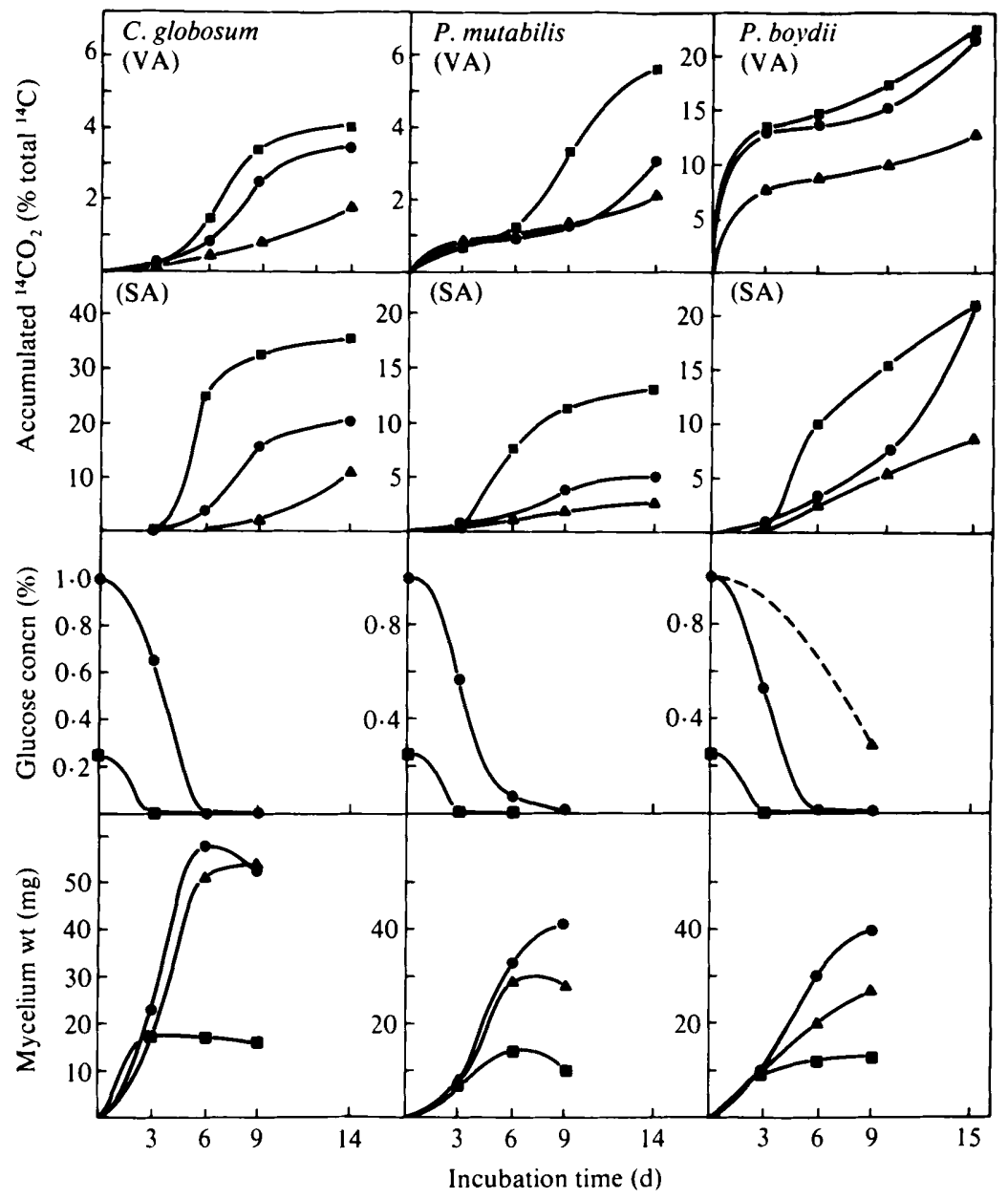

Fig. 3. Accumulated ${ }^{1+} \mathrm{CO}_{2}$ evolution from methoxyl-labelled vanillate (VA) and syringate (SA) by the soft-rot fungi $C$. globosum. Phialophora mutabilis and Petriellidium boydii on LH ( $), \mathrm{HL}(\Delta)$ and $\mathrm{HH}$ (O) media. Other conditions are as in Fig. 1. - - Approximate decrease. Final standard deviations $\left(\delta_{n-1}\right)$ for the ${ }^{1+} \mathrm{CO}_{2}$ values:

C. globosum

Phialophora mutabilis

Petriellidium boydii on VA: LH, $1.2 \% ; \mathrm{HL}, 0.72 \% ; \mathrm{HH}, 3.8 \%$ on SA: LH, $2.5 \%$; HL, $1.4 \%$; HH, $0.96 \%$ on VA: $\mathrm{LH}, 1.7 \%$; $\mathrm{HL}, 0.99 \%$; $\mathrm{HH}, 0.25 \%$ on SA: LH, $3.0 \%$; HL, $0.28 \%$; HH, $1.6 \%$ on VA : LH, $7.1 \%$, HL, $5.3 \%$; HH, $1.1 \%$ on SA : LH, $2.5 \%$; HL, $2.0 \%$; HH, $3.0 \%$

differences almost certainly reflect differences in inocula preparation, and in media and cultural conditions. The vanillate and syringate demethylating ability reported here for white-rot fungi, and also for brown-rot and soft-rot fungi, are in good agreement with the known ability of these fungi to demethylate lignin (Seifert, 1966; Ander \& Eriksson, 1978; Crawford, 1981), although due caution should be exercised when extrapolating results obtained with lignin model compounds to include the intact polymer. Thus, our unpublished results indicate that the soft-rot fungi used in this study do not release ${ }^{14} \mathrm{CO}_{2}$ from ring- or methoxyl-labelled synthetic lignin (DHP), although some of the soft-rot fungi used by Haider \& Trojanowski (1975) released small amounts of ${ }^{14} \mathrm{CO}_{2}$ from such lignin. On the other hand, degradation of lignin in wood by different soft-rot fungi, among them C. globosum, has been reported after prolonged incubation (Savory \& Pinion, 1958; Eslyn et al., 1975). 
The physiology of growth by $P$. ostreatus clearly requires further investigation. Our findings show that this fungus grows better in the presence of increased levels of $\mathrm{CO}_{2}$. This may explain the observed higher yield of ${ }^{14} \mathrm{CO}_{2}(26 \%)$ from methoxyl-labelled vanillate as compared to $10 \%$ ${ }^{14} \mathrm{CO}_{2}$ reported by Buswell et al. (1982a) for Pleurotus ostreatus on a similar medium. Results by Scháněl \& Dovrtěl (1980) further indicate that when Pleurotus ostreatus grows on wood, $\mathrm{CO}_{2}$ can stimulate peroxidase production. This may increase growth of the fungus.

In conclusion, the white-, soft- and brown-rot fungi tested were similar to each other in that the initial release of ${ }^{14} \mathrm{CO}_{2}$ from the methoxyl groups of vanillic and syringic acids in almost all cases occurred most rapidly in the presence of low amounts of glucose and high amounts of nitrogen. If wood-rotting fungi are used in the future for biotechnical applications in the pulp and paper industry, the glucose and nitrogen concentrations are clearly important parameters to consider.

We thank Dr Konrad Haider for the gift of labelled compounds.

\section{REFERENCES}

ANDER, P. \& ERIKsSON, K.-E. (1976). The importance of phenol oxidase activity in lignin degradation by the white-rot fungus Sporotrichum pulverulentum. Archives of Microbiology 109, 1-9.

ANDER, P. \& ERIKSSON, K.-E. (1978). Lignin degradation and utilization by micro-organisms. Progress in Industrial Microbiology 14, 1-58.

Ander, P., Hatakka, A. \& Eriksson, K.-E. (1980). Vanillic acid metabolism by the white-rot fungus Sporotrichum pulverulentum. Archives of Microbiology 125, 189-202.

ANDER, P., Eriksson, K.-E. \& YU, H.-S. (1983a). Physiological requirements for degradation of lignin and lignin-related substances by Sporotrichum pulverulentum. European Journal of Applied Microbiology and Biotechnology (in the Press).

ANDER, P., ERIKSSON, K.-E. \& YU, H.-s. (1983b). Vanillic acid metabolism by Sporotrichum pulverulentum: evidence for demethoxylation before ring-cleavage. Archives of Microbiology 136, 1-6.

Buswell, J. A., ERIKSSON, K.-E., GuPTA, J. K., HaMP, S. G. \& NORDH, I. (1982a). Vanillic acid metabolism by selected soft-rot, brown-rot and white-rot fungi. Archices of Microbiology 131, 366-374.

Buswell, J. A., ANDER, P. \& ERIKSSON, K.-E. (1982b). Ligninolytic activity and levels of ammonia assimilating enzymes in Sporotrichum pulverulentum. Archices of Microbiology 133, 165-171.

CRAWFORD, R. L. (1981). Lignin Degradation and Transformation. New York: John Wiley.

Eriksson, K.-E., Johnsrud, S. C. \& Vallander, L. (1983). Degradation of lignin and lignin model compounds by various mutants of the white-rot fungus Sporotrichum pulverulentum. Archives of Microbiology 135, 161-168.

ESLYN, W. E., KIRK, T. K. \& EFFLAND, M. J. (1975). Changes in the chemical composition of wood caused by six soft-rot fungi. Phytopathology 65,473 476.

FENN, P. \& KIRK, T. K. (1979). Ligninolytic system of Phanerochaete chrysosporium: inhibition by $o$-phthalate. Archives of Microbiology 123, 307-309.
Gupta, J. K., Hamp, S. G., Buswell, J. A. \& ERIKSSON, K.-E. (1981). Metabolism of trans-ferulic acid by the white-rot fungus Sporotrichum pulverulentum. Archives of Microbiology 128, 349-354.

HAIDER, K. \& TroJANOWSKI, J. (1975). Decomposition of specifically ${ }^{14} \mathrm{C}$-labelled phenols and dehydropolymers of coniferyl alcohol as models for lignin degradation by soft and white-rot fungi. Archives of Microbiology 105, 33-41.

Haider, K. \& TrojanowsKi, J. (1980). A comparison of the degradation of ${ }^{1+} \mathrm{C}$-labelled DHP and cornstalk lignins by micro- and macro-fungi and bacteria. In Lignin Biodegradation: Microbiology, Chemistry and Potential Applications, vol. 1, pp. 111-134. Edited by T. K. Kirk, T Higuchi \& H.-M. Chang. Boca Raton: CRC.

Henderson, M. E. K. (1961). Isolation, identification and growth of some soil hyphomycetes and yeast-like fungi which utilize aromatic compounds related to lignin. Journal of General Microbiology 26, 149-154.

HeNDERSON, M. E. K. (1963). Fungal metabolism of certain aromatic compounds related to lignin. Pure and Applied Chemistry 7, 589-602.

KIRK, T. K. (1981). Toward elucidating the mechanism of action of the ligninolytic systems in basidiomycetes. In Trends in the Biology of Fermentations for Fuels and Chemicals, pp. 131-149. Edited by A. Hollaender. New York: Plenum Publication Corporation.

Kuellman, M. \& RÁdeström, R. (1981). Glucose determination with glucose oxidase (in Swedish). Swedish Forest Products Research Laboratory, AH 23-5, STFI/AS.

Savory, J. G. \& Pinion, L. C. (1958). Chemical aspects of decay of beech wood by Chaetomium globosum. Holzforschung 12, 99-103.

SCHÁNĚL, L. \& DOVRTĚL, J. (1980). The effect of $\mathrm{CO}_{2}$ on the metabolic activity of wood-destroying fungi (in Russian). Drevársky Viskum 25, 47-51.

SEIFERT, K. (1966). Die chemische Veränderung der Buchenholz-Zellwand durch Moderfäule (Chaetomium globosum Kunze). Holzforschung 24, 185-189. 